\title{
Enhanced lifetime of methane bubble streams within the deep ocean
}

\author{
Gregor Rehder, ${ }^{1}$ Peter W. Brewer, Edward T. Peltzer, and Gernot Friederich \\ Monterey Bay Aquarium Research Institute, Moss Landing, California, USA
}

Received 23 August 2001; revised 16 July 2002; accepted 26 July 2002; published 7 August 2002.

[1] We have made direct comparisons of the dissolution and rise rates of methane and argon bubbles experimentally released in the ocean at depths from 440 to $830 \mathrm{~m}$. The bubbles were injected from the ROV Ventana into a box open at the top and the bottom, and imaged by HDTV while in free motion. The vehicle was piloted upwards at the rise rate of the bubbles. Methane and argon show closely similar behavior at depths above the methane hydrate stability field. Below that boundary $(\sim 520 \mathrm{~m})$ markedly enhanced methane bubble lifetimes are observed, and are attribute to the formation of a hydrate skin. This effect greatly increases the ease with which methane gas released at depth, either by natural or industrial events, can penetrate the shallow ocean layers. INDEX TERMS: 4820 Oceanography: Biological and Chemical: Gases; 4806 Oceanography: Biological and Chemical: Carbon cycling; 3022 Marine Geology and Geophysics: Marine sediments - processes and transport

\section{Introduction}

[2] Knowledge of the mechanism and rates of vertical oceanic transport of methane is important for understanding the fate of natural (seepage) and industrial (pipeline and well head) releases today. It has long been recognized that at depths below about 500 $\mathrm{m}$, methane forms a solid hydrate in the ocean [Sloan, 1997], and both the size of this hydrate reservoir, and its stability are important topics of debate. Hydrate layers in the sediment may seal the seafloor, capturing large amounts of free gas below the hydrate stability field. Slump slides associated with gas and hydrate instability have been described, leading to the release of large amounts of free gas from below the hydrate stability field into the water column [Paull et al., 1991]. Release of free gas into the water column well within the hydrate stability field is known today from Hydrate Ridge, Cascadia margin [Suess et al., 2001], from Blake Ridge at the Carolina continental rise [Paull et al., 1995], from the Guayamas Basin [Merewether et al., 1985], and from the Gulf of Mexico [MacDonald et al., 1994].

[3] The deep ocean contains only trace amounts of methane [Scranton and Brewer, 1978]. Thus a bubble plume from gas seepage or release at depth creates an enormous driving force for dissolution, and methane dissolved at depth will be microbially transformed to $\mathrm{CO}_{2}$ on a time scale shorter than the ventilation time of deep water masses [Rehder et al., 1999; Warner et al., 1996]. Only a fraction of $\mathrm{CO}_{2}$ produced in the deep ocean would enter the atmosphere due to the ocean's storage capacity for $\mathrm{CO}_{2}$, and the radiative forcing potential of $\mathrm{CO}_{2}$ is smaller than that of methane [Lelieveld et al., 1998]. As a consequence, the global warming potential of a mole of methane oxidized to $\mathrm{CO}_{2}$ in the \footnotetext{
Germany. (grehder@geomar.de)

${ }^{1}$ Now at GEOMAR Research Center, Wischhofstr, 1-3, D-24148 Kiel, deep ocean is about a factor of 50 smaller than that of methane released to the atmosphere without conversion.

[4] If however methane dissolution is inhibited during bubble transport within the hydrate stability zone, then upward transport to depths close to or even within the winter mixed layer, which are ventilated on far shorter time scales, is possible. Here we report on direct measurements of the rise rate and dissolution rate of bubbles of both methane and (for comparison) argon in the deep sea. The purpose of the experiments was to determine whether the dissolution rate of methane bubbles in free ascent is significantly decreased within the hydrate stability field due to the formation of a hydrate skin.

\section{Experimental}

[5] Measurements were made using MBARIs ROV Ventana in Monterey Bay, California, where the upper boundary of the methane hydrate stability field is close to $520 \mathrm{~m}$ depth [Peltzer and Brewer, 2000] (see auxiliary material, GRL online ${ }^{1}$ ). Single gas bubbles were released from compressed gas cylinders through a 1/4-inch stainless steel nozzle at various depths between 820 and $430 \mathrm{~m}$ into an imaging box attached to the ROV (Figure 1). The ROV was piloted upwards at a speed adjusted to match the rise velocity of the bubbles, and the ascent of individual bubbles within the imaging box was recorded using an HDTV camera system (see suppl. material, GRL online). The bubbles initially had an ellipsoidal shape with an initial equivalent diameter between 5 and 9 $\mathrm{mm}$. The equivalent diameter (i.e. the diameter of a sphere with the same volume) was calculated using the relation $\mathrm{d}_{e}=\left(\mathrm{a}^{2} \mathrm{~b}\right)^{1 / 3}$, where $\mathrm{a}$ and $\mathrm{b}$ are the long and the short axis of the ellipsoid, respectively [Sam et al., 1996]. The imaging box ( $89 \mathrm{~cm}$ long, $25 \mathrm{~cm}$ deep, 30 $\mathrm{cm}$ wide) restrained lateral motions, while permitting almost undisturbed upward motion of the gas bubble. The backwall consisted of two opaque PVC plates spaced $8 \mathrm{~cm}$ apart, reducing visual clutter from the ubiquitous background of marine snow and acting as diffusers for four light sources mounted behind the second wall.

[6] Argon served as a reference gas in the experiments. A wide range of parameters, including coverage with surfactants, different shapes depending on bubble size, temperature, and hydrostatic pressure can influence the dissolution kinetics of a single bubble [Clift et al., 1978; Leifer et al., 2000]. These parameters are quite variable in the ocean and some of them are not well established. The only gas-specific parameter used in theoretical descriptions of gas dissolution kinetics is the quotient of the solubility and the square root of the Schmidt number $\left(\beta / \mathrm{Sc}^{0.5}\right)$ [Clift et al., 1978]. In the temperature range in which the experiments were carried out $\left(4-7.5^{\circ} \mathrm{C}\right), \beta / \mathrm{Sc}^{0.5}$ is almost identical for methane and argon [Wanninkhof, 1992] (see suppl. material, GRL online), but argon does not form hydrates under these P,T-conditions [Marshall et al., 1964]. By comparing the behavior of both gases in experiments performed under identical oceanic conditions, the uncertainties

\footnotetext{
${ }^{1}$ Supporting material is available via Web browser or via Anonymous FTP from ftp://ftp.agu.org, directory "apend" (Username = "anonymous", Password = "guest"); subdirectories in the ftp site are arranged by paper number. Information on searching and submitting electronic supplements is found at http://www.agu.org/pubs/esupp_about.html.
} 


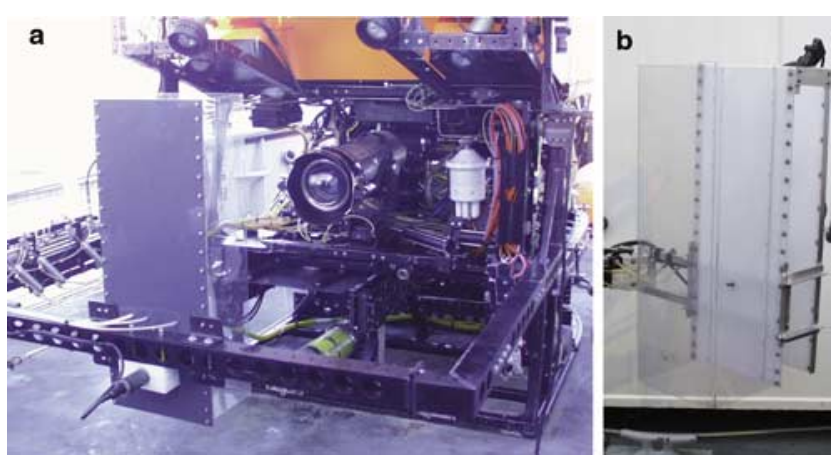

Figure 1. (a) ROV Ventana before the dive with the imaging box mounted in front of the HDTV camera. An array of hydraulic valves was used for the release of different gases (left side). (b) Modified imaging box using a set of two opaque back walls and illumination from the back.

involved in the parameterizations needed to derive the absolute dissolution rate are avoided.

\section{Results}

\subsection{Bubble Rise Rates}

[7] The rise rate of the gas bubbles was determined in two ways. The pressure log of the ROV provides data on the change of depth of the bubbles with time, and the (dynamic) rise velocity can be derived from the slope of this function. For comparison with the "vehicle in motion" experiments, the rise rate was also determined with the ROV stationary on the seafloor $\left(847 \mathrm{dbar} ; 4.5^{\circ} \mathrm{C}\right)$. HDTVframes were taken at least $15 \mathrm{~cm}$ above the nozzle, and the distance traveled was typically $60 \mathrm{~cm}$. The mean rise velocity of argon (25.1 $\mathrm{cm} / \mathrm{sec} \pm 0.21 \mathrm{~cm} / \mathrm{sec} ; \mathrm{N}=11$ ) was about $5 \%$ smaller than for methane $(26.3 \mathrm{~cm} / \mathrm{sec} \pm 0.4 \mathrm{~cm} / \mathrm{sec} ; \mathrm{N}=9)$. This reflects the buoyant forces driving the ascent due to the different densities of methane and argon at depth (see suppl. material, GRL online).

[8] The mean dynamic rise rate was $28.3 \pm 1.7 \mathrm{~cm} / \mathrm{s}$ and 29.2 $\pm 1.8 \mathrm{~cm} / \mathrm{s}$ for argon and methane, respectively (Figure 2a). This is about $12 \%$ larger than the result obtained from the static experiment, which implies that the drag produced by the walls of the imaging box had only small impact on the rise velocity. While the bubbles shrank significantly during ascent, the rise rate stayed almost constant (Figure 2). The rise velocity of bubbles is a function of size [Clift et al., 1978], but the bubbles monitored fall in the range where this effect is small. Apparently, the effects of changing diameter, increasing density difference between gas and ambient seawater, and changing shape of the bubble all combined to yield a constant rise rate within the error of our measurements.

\subsection{Bubble Dissolution}

[9] The equivalent diameter of argon bubbles at all depths (between 830 and $360 \mathrm{~m}$ ) decreased linearly with time (Figure $2 b$ ). The shrinking rate was very consistent at all depths, with a mean rate of $18.9 \pm 2.2 \mu \mathrm{m} / \mathrm{sec}$. Methane above the hydrate stability field (Figure 2b) showed the same linear trend and consistent behavior as argon, although the bubbles dissolved somewhat more slowly $(15.5 \pm 3.2 \mu \mathrm{m} / \mathrm{sec})$. Within the hydrate stability field, the behavior was completely different (Figure 2c). After an initial stage of fast dissolution, with a rate comparable to that of methane bubbles released above the hydrate stability field (mean $12.8 \mu \mathrm{m} / \mathrm{sec}$ ), the shrinking rate markedly slowed by a factor of 3.5 to $6($ mean $3.0 \mu \mathrm{m} / \mathrm{s})$. The transition appeared at $\mathrm{d}_{e}=3.5$ to 4 $\mathrm{mm}$, with one exception at $\mathrm{d}_{e}=2.3 \mathrm{~mm}$. Gas bubbles with a reduced shrinking rate also had a more spherical appearance (Figure 3a). The difference in dissolution behavior within and out of the hydrate stability field for methane was not found for argon, and can thus be attributed to a gas specific process, most likely the nucleation of a hydrate skin.

[10] For methane bubbles released within the stability field and in the state of slow dissolution, shape and path oscillations were suppressed. The low shrinking rate and non-oscillatory motion remained after the bubbles left the hydrate stability field, suggesting strong residual order in the boundary layer.

\subsection{Observations in a Natural System}

[11] Field observations made at Hydrate Ridge, Oregon, suggest that the observed effect exists strongly in natural systems. We monitored the rise of natural gas bubbles, emerging from the seafloor at the southern summit of Hydrate Ridge, Oregon, at a water depth of $780 \mathrm{~m}$. The gas consists of $>98 \%$ methane [Peltzer et al., 2000], and the upper boundary of the methane
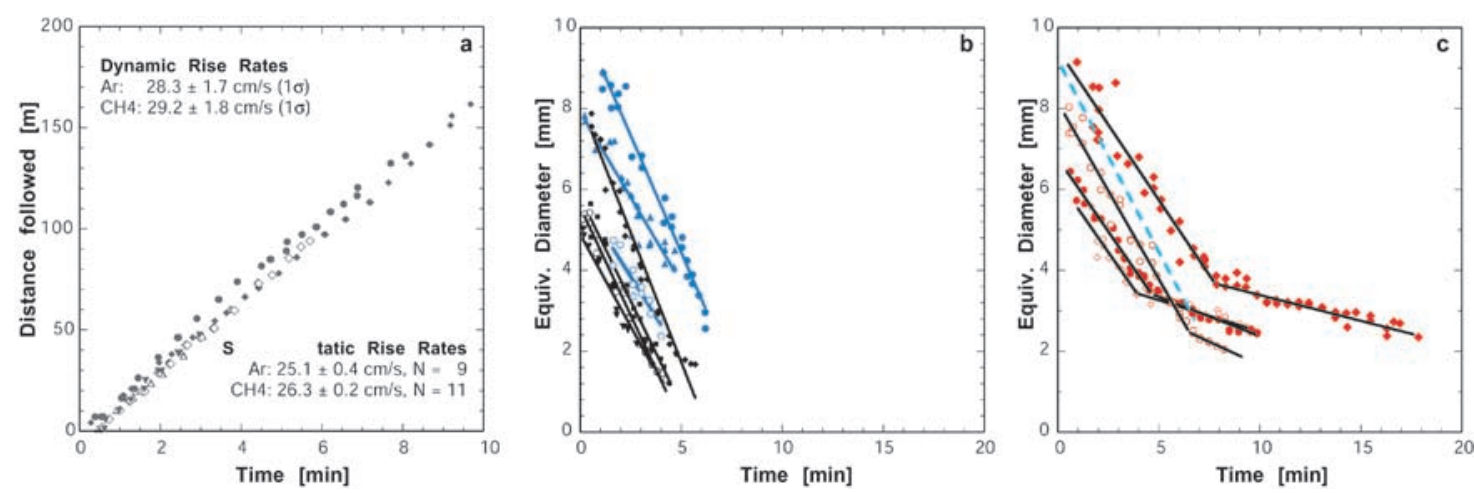

Figure 2. (a) Rise distance of single bubbles after release. The slope of this function represents the (dynamic) bubble rise velocity. The mean rise rate for methane (filled symbols) was slightly higher than for argon (open symbols). For methane, the rise rate for bubbles released within the hydrate stability field (points and diamonds) and above the hydrate stability field (triangles) was undistinguishable. Also given are the results of the (static) rise rate measurements with the ROV stationary at the seafloor at 847 dbar. (b) Decrease of the equivalent diameter $\left(\mathrm{d}_{e}\right)$ of single bubbles during the ascent versus time. Argon bubbles (black symbols) shrink with a consistent rate of $18.9 \pm 2.2 \mu \mathrm{m} / \mathrm{sec}$ in the entire depths range covered $(830-440 \mathrm{~m}$ release depth). Methane bubbles above the hydrate stability (blue symbols) dissolve at a similar rate $(15.5 \pm 3.3 \mu \mathrm{m} / \mathrm{sec}$ ). (c) Same as Figure $2 \mathrm{~b}$ but for methane bubbles released within the hydrate stability field. The data follow a bilinear trend, suggesting a drastic change in behavior after transition from a state without hydrate effect to a stage with the influence of a hydrate skin. The slope of the first part (mean $12.8 \mu \mathrm{m} / \mathrm{sec}$ ) is close to the average shrinking rate observed on $\mathrm{CH}_{4}$ bubbles out of the hydrate stability field (blue hatched line). The slopes after the transition average $3.0 \mu \mathrm{m} / \mathrm{sec}$. 


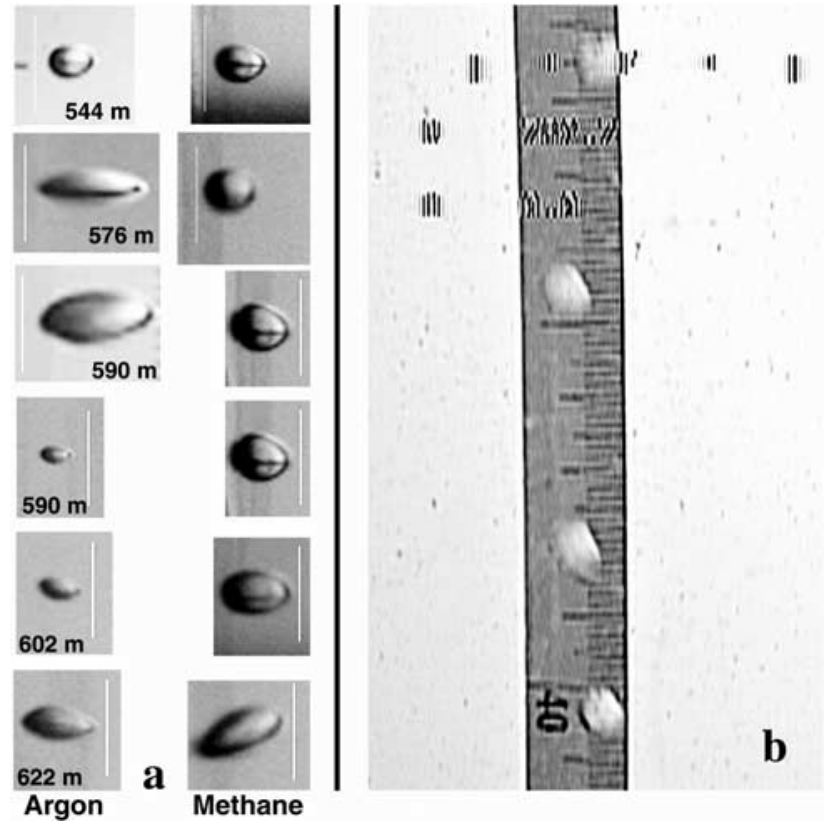

Figure 3. (a) Development of the size of two argon bubbles (left) and a $\mathrm{CH}_{4}$ bubble (right) between 622 and $544 \mathrm{~m}$ water depth. The length of the white scale bar is $1 \mathrm{~cm}$. (b) Bubbles of natural gas at the seafloor at $780 \mathrm{~m}$ depth, showing a spherical appearance immediately after contact with the seawater.

hydrate stability field was at $\sim 500 \mathrm{~m}$. Bubbles were about $6-7$ $\mathrm{mm}$ in diameter at the source, but appeared to have an almost spherical shape immediately on emerging from the sediment (Figure 3b). This unusual shape for a bubble of this size indicates the presence of a more rigid surface, which suggests that a hydrate skin has already been formed when the bubble leaves the seabed.

\section{Discussion}

[12] The growth of hydrate on the gas-water interface requires two steps. The initial formation of a hydrate nucleus, and growth of hydrate after the nucleation site has formed. The onset of hydrate formation on a plane water/gas interface has been shown to be almost immediate in water which has been in contact with hydrates before, while it could take times long compared to a bubble lifetime in distilled water or fresh tap water [Vysniauskas and Bishnoi, 1983]. This is explained by the preservation of water microstructures favoring hydrate nucleation and growth [Sloan, 1997]. For a certain water environment, time of nucleation in multiple experiments is randomly distributed. In laboratory experiments on methane and natural gas bubbles, it has been shown that nucleation was delayed in newly replaced water and that pressures considerably in excess of the equilibrium pressure were required for this case [Maini and Bishnoi, 1981; Topham, 1984]. After hydrate had once been formed in the system, the nucleation process was accelerated dramatically in following nucleation experiments. Our observations of natural and artificial bubbles are in agreement with these findings. In case of the artificial release in Monterey Bay, the gas was surrounded by water that had not had any contact with hydrates before, and it took in general a long — and unpredictable - time before the onset of nucleation. Lateral spreading of hydrate along a gas/water interphase after nucleation is a very rapid process, which explains the sharp transfer to the skin-covered condition (Figure 2c). In contrast, gas hydrates and free gas have been found in the upper sediment layer of the southern summit of Hydrate Ridge [Suess et al., 2001]. Thus, it is more than likely that the porewaters in contact with these hydrates should contain the water precursors required for hydrate nucleation, which should yield to the immediate presence of a hydrate skin on the gas bubbles emerging the seafloor at this site, in accordance with our observations.

[13] Our experiments and observations show that hydrate nucleation on a methane bubble can occur even in a highly undersaturated water column. The methane concentration in the water column below $500 \mathrm{~m}$ in Monterey Bay is $\sim 1 \mathrm{nmol} / \mathrm{l}$, which is typical for the oceanic methane background [Rehder et al., 1999; Scranton and Brewer, 1978]. Seawater $\mathrm{CH}_{4}$ concentrations in the vicinity of Hydrate Ridge are enhanced due to several processes, but measurements on the northern summit in July, 2000, were always below $100 \mathrm{nmol} / 1$ and hence, negligible compared to the in situ saturation value (data not shown). The reduced shrinking rate has considerable impact on the upward transport of methane through the water column. Using the mean rise rate of $28.7 \mathrm{~cm} /$ $\mathrm{sec}$ and a shrinking rate of $12.8 \mu \mathrm{m} / \mathrm{s}$ and $3 \mu \mathrm{m} / \mathrm{s}$ for a non-hydratecoated and a hydrate-coated bubble, respectively, we calculate the mass loss of a bubble of an initial size of $7 \mathrm{~mm}$, released at $800 \mathrm{~m}$ water depth. The bubble without a hydrate skin would loose $50 \%$ of its mass after $106 \mathrm{sec}$, or $30 \mathrm{~m}$. In contrast, a bubble with a hydrate film, assumed to shrink with a rate of $3 \mu \mathrm{m} / \mathrm{sec}$, would travel $110 \mathrm{~m}$ before half of its mass would be dissolved (see suppl. material, GRL online).

[14] The slowing of the dissolution rate of methane bubbles within the hydrate stability field provides a mechanism by which methane gas released from the seafloor can be efficiently transported above the hydrate stability boundary. Methane is oxidized in the open ocean on a time scale of decades or longer [Rehder et al., 1999; Scranton and Brewer, 1978], which is short compared to the ventilation time of the deep oceans $(\sim 500 \mathrm{yrs}$ Pacific; $\sim 250 \mathrm{yrs}$ Atlantic), but long compared to the annual ventilation by winter mixing of the upper few hundred meters of the water column [Warner et al., 1996]. In some areas of the ocean, the upper boundary of the methane hydrate stability field is even shallower than the maximum depth of the mixed layer in winter [Harvey, 1982]. Thus, this transport mechanism increases the possibility for a direct interaction of methane released from deep water gas sources with the atmosphere. Our findings increase understanding of the methane distribution above modern deep gas vents and gas leakage from under-sea pipelines, and will help to refine scenarios of ancient, present, and future climate feedback associated with methane releases.

[15] Acknowledgments. We thank the crews of R/V Point Lobos and $\mathrm{R} / \mathrm{V}$ Western Flyer and the ROV technicians and pilots of ROV Ventana and Tiburon for their skillful support during offshore operation. We are indebted to Chris Rodgers-Walz and Kyra Schlining for invaluable and friendly help in the digital and video labs. Comments from Ira Leifer, University of California Santa Barbara, considerably helped to improve this manuscript. This work was supported by a grant to MBARI from the David and Lucile Packard foundation.

\section{References}

Clift, R., J. R. Grace, and M. E. Weber, Bubbles, Drops, and Particles, 380, Academic Press, New York, 1978.

Harvey, J., Theta-S relationships and water masses in the eastern North Atlantic, Deep-Sea Res., 29A, 1021-1033, 1982.

Leifer, I., R. K. Patro, and P. Bowyer, A study on the temperature variation of rise velocity for large clean bubbles, J. Atmospheric and Oceanic Technology, 17, 1392-1402, 2000.

Lelieveld, J., P. J. Crutzen, and F. J. Dentener, Changing concentration, lifetime, and climate forcing of atmospheric methane, Tellus, 50, $128-$ $150,1998$.

MacDonald, I. R., N. L. Guinasso Jr., R. Sassen, J. M. Brooks, L. Lee, and K. T. Scott, Gas hydrate that breaches the sea floor on the continental slope of the Gulf of Mexico, Geology, 22, 699-702, 1994.

Maini, B. M., and P. R. Bishnoi, Experimental investigation of hydrate formation behaviour of a natural gas bubble in a simulated deep sea environment, Chem. Engineering Science, 36, 183-189, 1981.

Marshall, D. R., S. Saito, and R. Kobayashi, Hydrates at high pressures: 
Part I. Methane-water, argon-water, and nitrogen-water systems, $A I C h E$ Journal, 10, 202-205, 1964.

Merewether, R., M. S. Olsson, and P. Lonsdale, Acoustically detected hydrocarbon plumes rising from 2-km depths in Guayamas Basin, Gulf of California, J. Geophys. Res., 90, 3075-3085, 1985.

Paull, C. K., W. Ussler III, and W. P. Dillon, Is the extend of glaciation limited by marine gas-hydrates, Geophys. Res. Lett., 18, 432-434 1991.

Paull, C. K., W. Ussler III, W. S. Borowski, and F. N. Spiess, Methane-rich plumes on the Carolina continental rise: Associations with gas hydrates, Geology, 23, 89-92, 1995.

Peltzer, E. T., and P. G. Brewer, Practical physical chemistry and empirical predictions of methane hydrate stability, in Natural Gas Hydrate in Oceanic and Permafrost Environments, edited by M. D. Max, 17-28, Kluwer Academic Publishers, Dordrecht, 2000.

Peltzer, E., D. Donohoue, C. K. Paull, G. Rehder, G. Friederich, W. Ussler, and P. G. Brewer, Novel observations of vent gas chemistry, and evidence for the presence of structure $\mathrm{H}$ hydrate (Abstract), Eos Trans., AGU 8 , (Fall Meeting Supplement), F637, 2000.

Rehder, G., R. S. Keir, E. Suess, and M. Rhein, Methane in the northern Atlantic controlled by oxidation and atmospheric history, Geophys. Res. Lett., 26, 587-590, 1999.

Sam, A., C. O. Gomez, and J. A. Finch, Axial velocity profiles of single bubbles in water/frother solutions, Int. J. Miner. Process., 47, 177-196, 1996.
Scranton, M. I., and P. G. Brewer, Consumption of dissolved methane in the deep ocean, Limnol. Oceanogr., 23, 1207-1213, 1978.

Sloan, E. D., Clathrate hydrates of natural gases, Marcel Dekker, Inc., New York, 1997.

Suess, E., et al., Sea floor methane hydrates at Hydrate Ridge, Oregon, in Natural Gas Hydrates: Occurance, Distribution, and Detection, edited by C. K. Paull and W. P. Dillon, pp. 87-98, American Geophysical Union, Washington, DC, 2001.

Topham, D. R., The formation of gas hydrates on bubbles of hydrocarbon gases rising in seawater, Chemical Engineering Science, 39, 821-828, 1984.

Vysniauskas, A., and P. R. Bishnoi, A kinetic study of methane hydrate formation, Chemical Engineering Science, 38, 1061-1072, 1983

Wanninkhof, R., Relationship between wind speed and gas exchange over the ocean, J. Geophys. Res, 97, 7373-7382, 1992.

Warner, M. J., J. L. Bullister, D. P. Wisegarver, R. H. Gammon, and R. F. Weiss, Basin-wide distributions of chlorofluorocarbons CFC-11 and CFC12 in the North Pacific, J. Geophys. Res, 101, 20,525-20,542, 1996.

G. Rehder, P. G. Brewer, E. T. Peltzer, and G. Friederich, Monterey Bay Aquarium Research Institute, 7700 Sandholdt Road, Moss Landing, CA 95039, USA. (grehder@mbari.org; brpe@mbari.org; etp3@mbari.org; frge@mbari.org) 